nodos $y$ nudos

\title{
Temas de Red
}

\section{(2)} 6. 20.4

2.t.

1.)

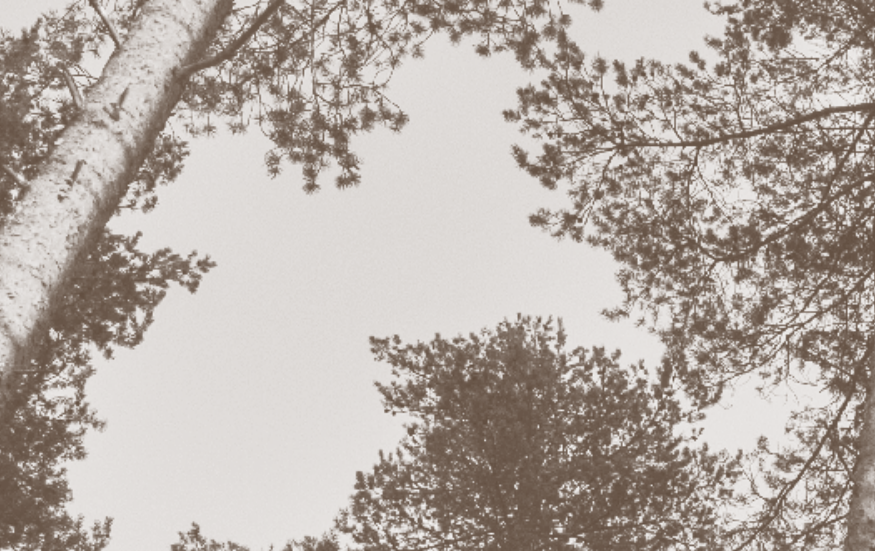

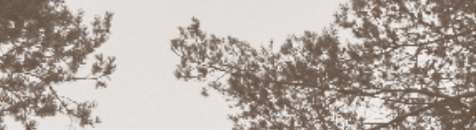

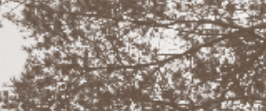

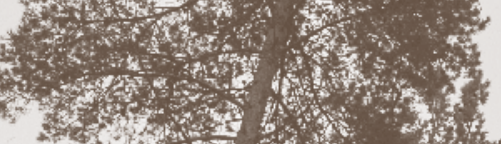

$10 \frac{3+2}{2}+1$

ty

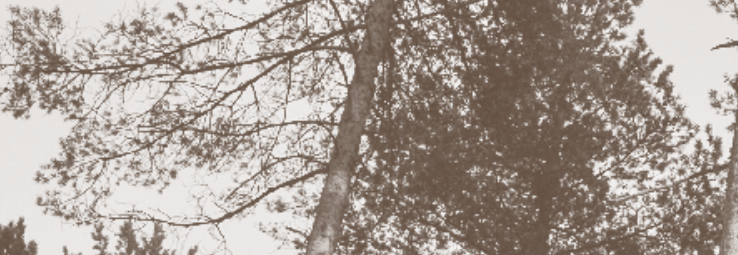

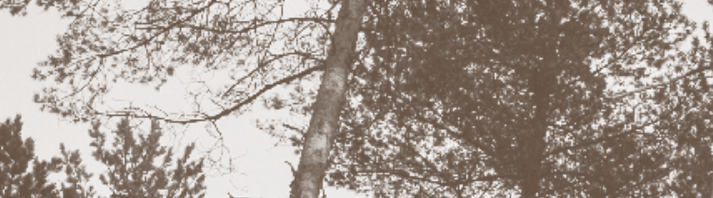

列

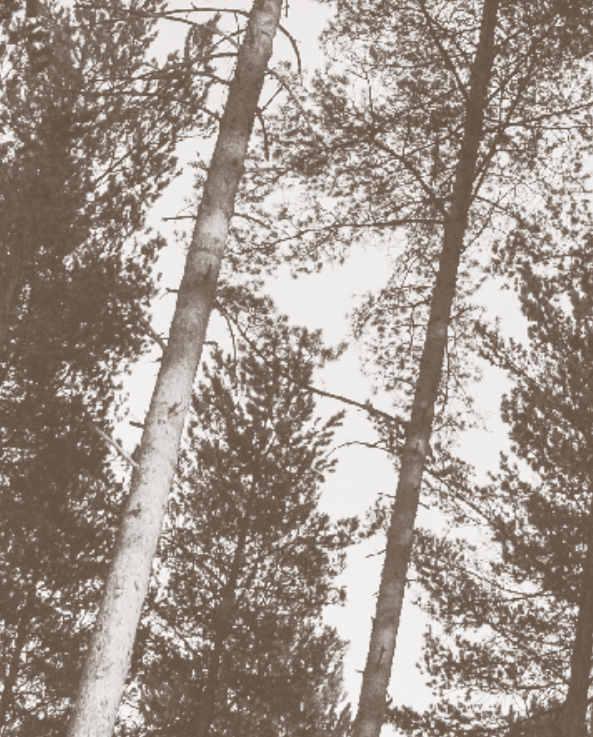

8

(2)

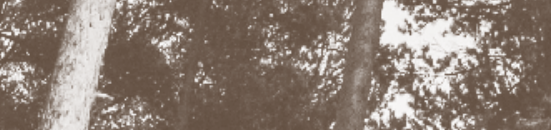

$+\infty$ of

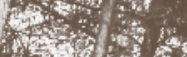

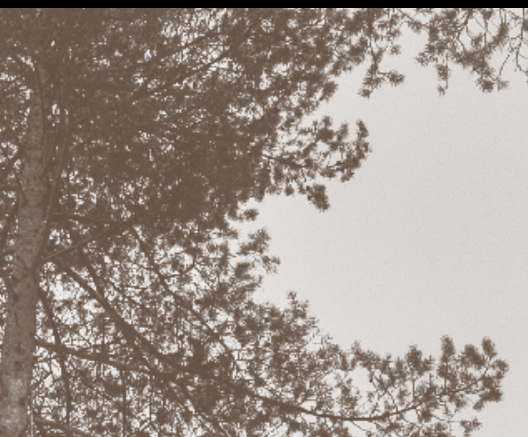

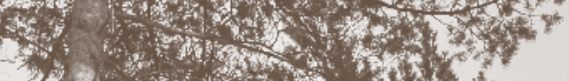

7.

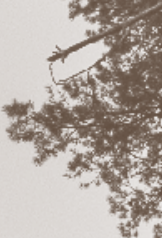
W. \% (4)

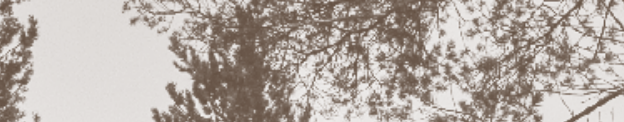

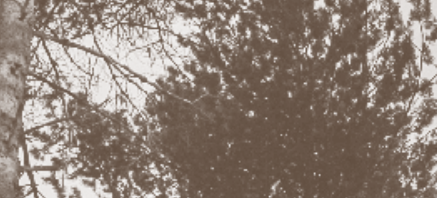

to

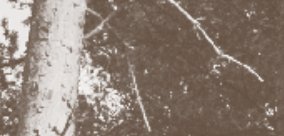


n

15
$7 \%$

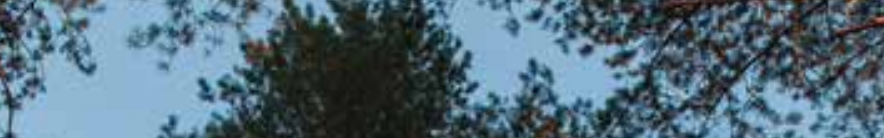
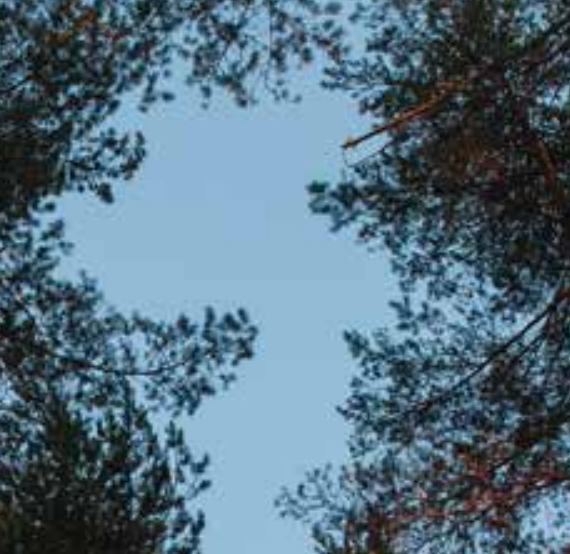

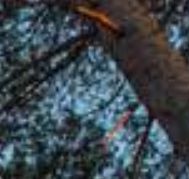
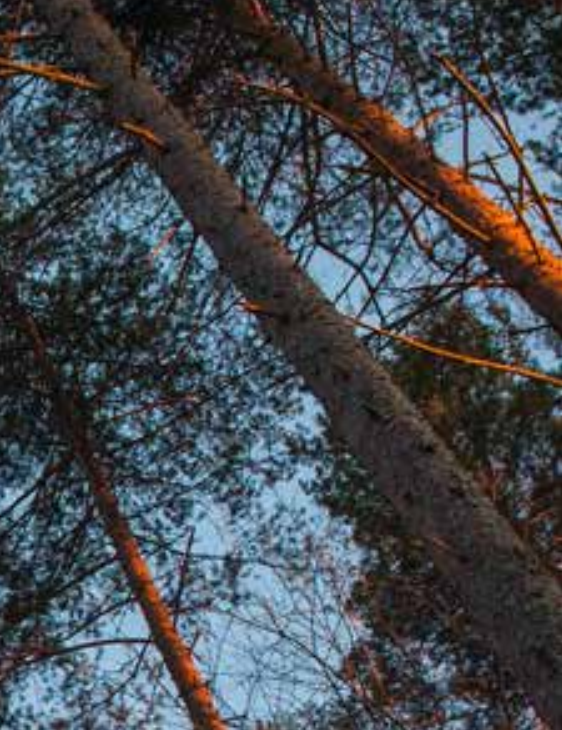

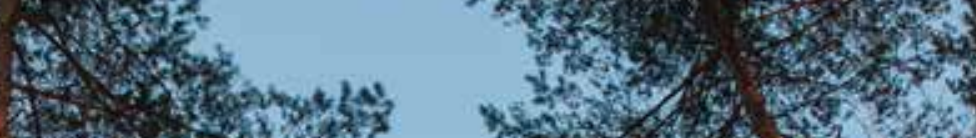
ing
9 sing

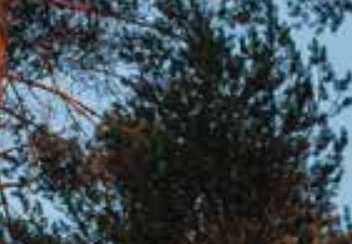

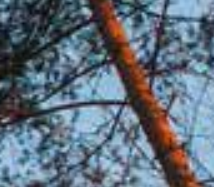

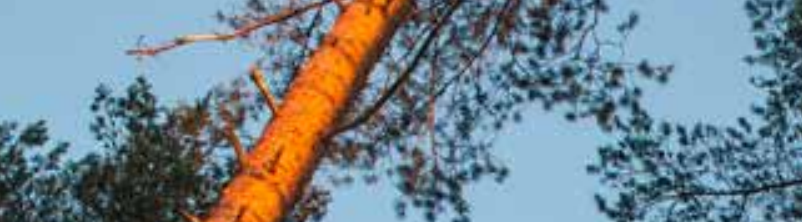

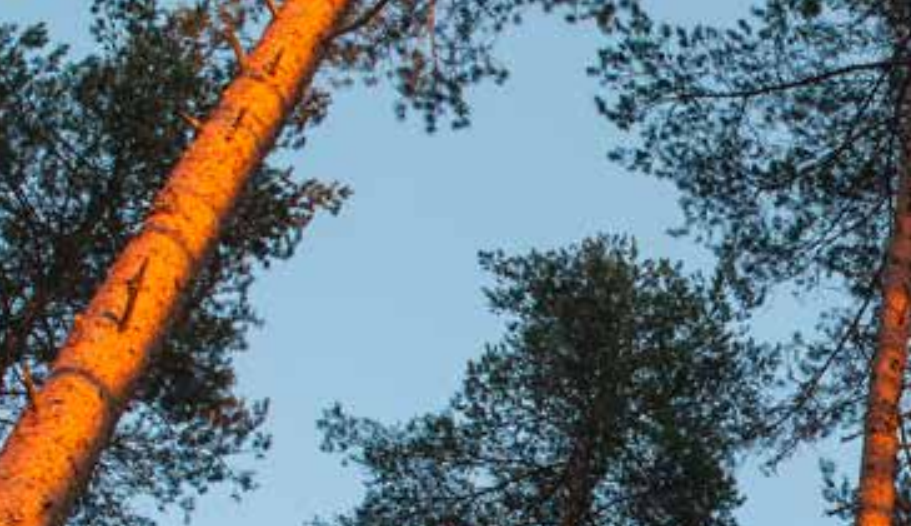

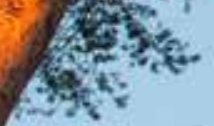

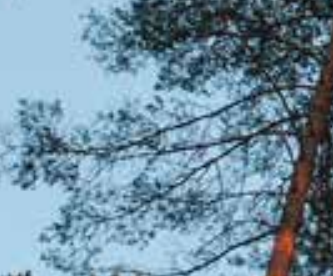

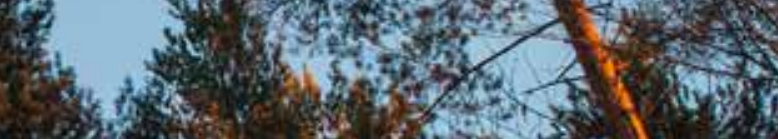
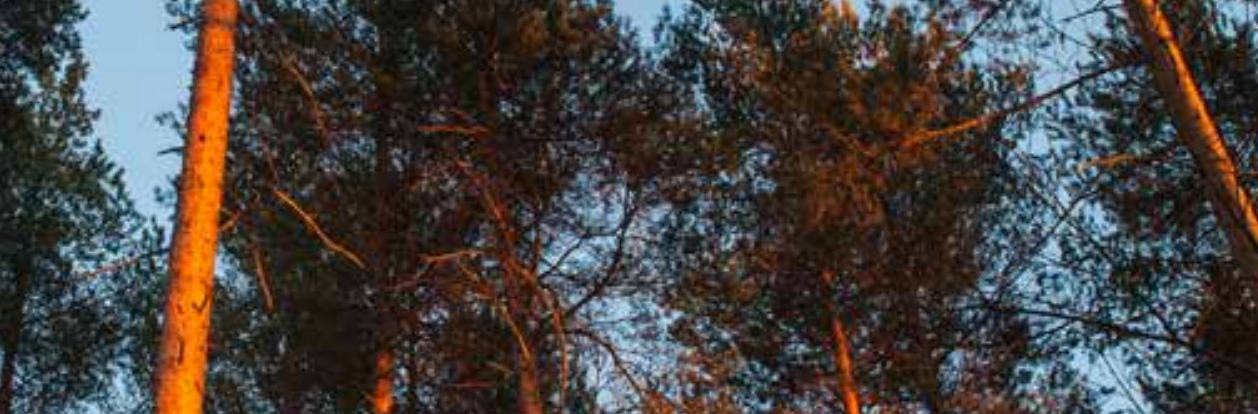

4. (v)

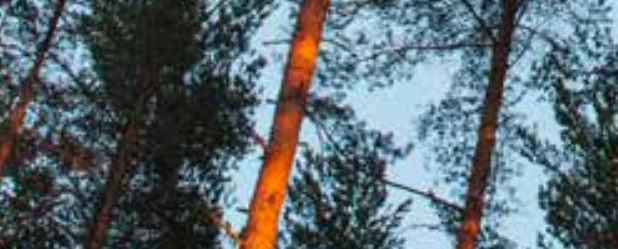
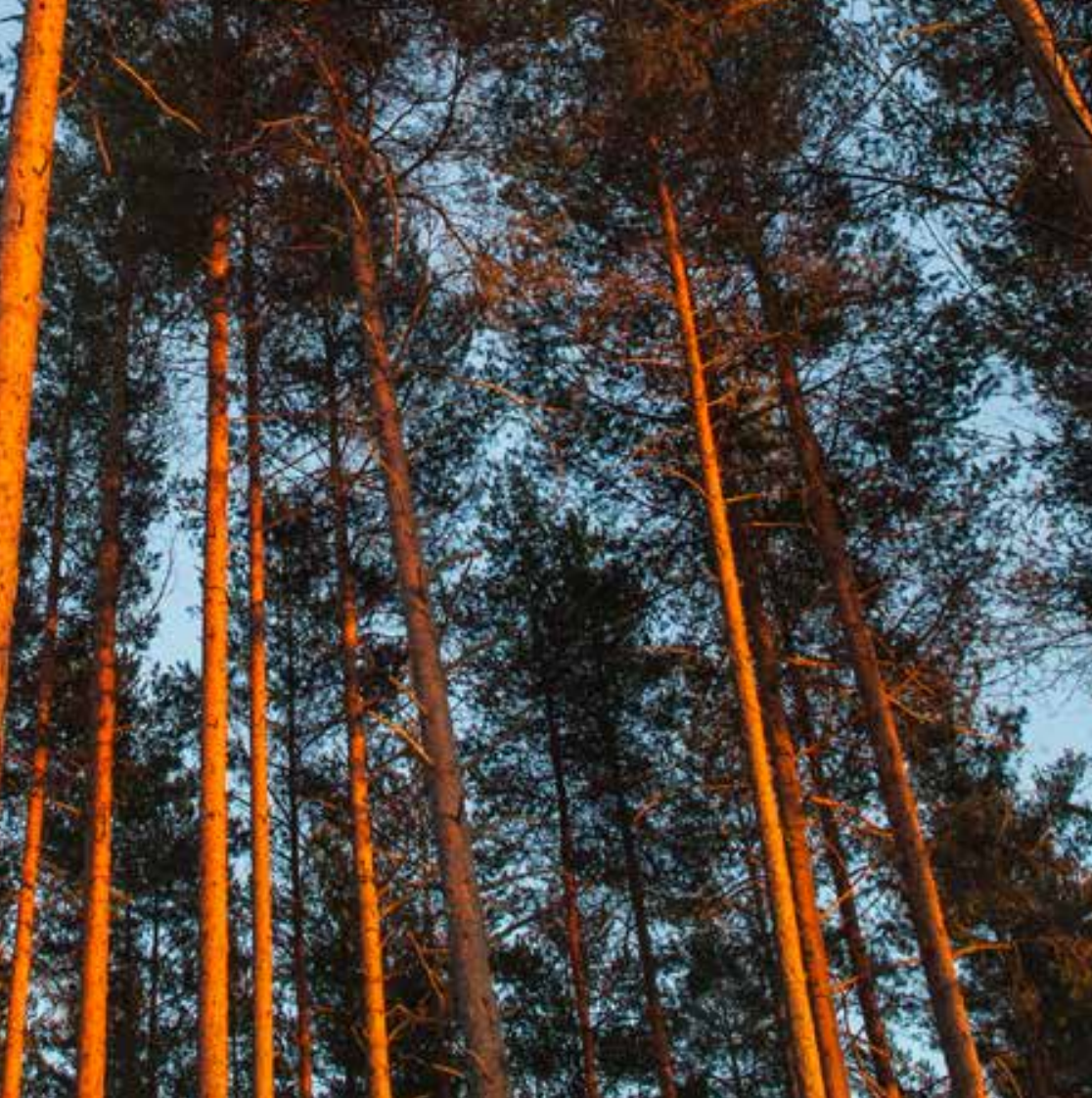

(1) $50 \times 5$

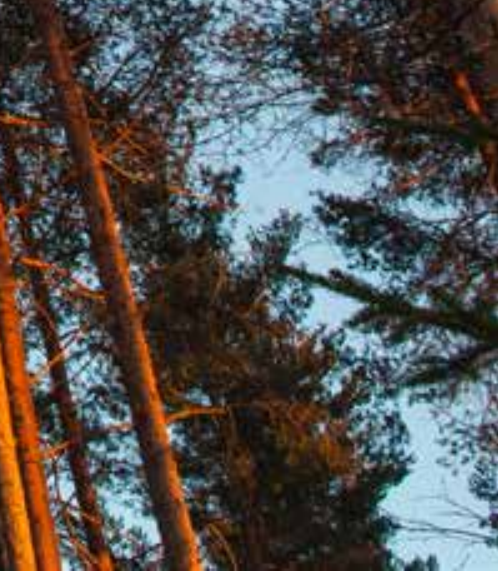

Autora: Ileana Álvarez Reyes

Título: Hilos de vida

Lugar: Løten, Noruega 


\section{La sistematización de experiencias educativas en la pedagogía decolonial}

Volumen $5 \mathrm{~N} .{ }^{\circ} 44$ enero - junio de 2018

ISSN: 0122-4328

ISSN-E: 2619-6069

pp. 15-34

Systematization

of Educational

Experiences in

De-colonial

Pedagogy
A sistematização

de experiências

educativas em

pedagogia

decolonial

Elisabet Rodríguez Vargas*

Fecha de recepción: 30-09-2017

Fecha de aprobación: 13-05-2018

\section{PARA CITAR ESTE ARTÍCULO}

Para citar este artículo Rodríguez, E. (2018). La sistematización de experiencias educativas en la pedagogía decolonial. Nodos y Nudos, 5(44), 15-34.
Licenciada en Ciencias Sociales y especialista en Desarrollo Humano con énfasis en Procesos Afectivos y Creatividad, de la Universidad Distrital Francisco José de Caldas; magister en Educación de la Universidad Pedagógica Nacional. Docente e investigadora. elisabet.natural@gmail.com 


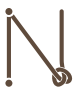

Volumen $5 \mathrm{~N} .{ }^{\circ} 44$ enero - junio de 2018 ISSN: 0122-4328 ISSN-E: 2619-6069 pp. $15-34$

\section{RESUMEN}

En el documento se presenta la fundamentación la sistematización de Experiencias Educativas (see) como una metodología que permite la visibilización de lo que hegemónicamente ha permanecido ausente y de esta manera busca resignificarlo y legitimarlo, potenciando de este modo la producción de saberes desde la experiencia de las comunidades. También se definen la emergencia de la (see), así como su recorrido histórico, la constitución de sus estrategias y herramientas, así como los pasos y fases de la aplicación de dicha metodología. Por último, se plantean a partir de los análisis de la experiencia pedagógica la posibilidad de construcción de pedagogias Otras, como la pedagogía de la conexión, producidas desde la experiencia y en diálogo con los aportes teóricos-metodológicos presentados en esta investigación.

Palabras clave: sistematización de experiencias; pedagogía; metodologías de investigación

\section{ABSTRACT}

This article presents the basis of the Systematization of Educational Experiences (SEE) as a methodology that enables visibility of what hegemonically has been absent and in this way, it aims at re-signifying it and legitimizing it by enhancing the production of knowledge from community experiences. The emergence of SEE is defined and also its historical course, the constitution of its strategies and tools and phases for implementing this methodology. Finally, we pose the possibility for constructing "other" pedagogies from the analysis of the pedagogical experiences, such as the pedagogy of connection, produced from experience and related with the theoretical and methodological contributions presented in this investigation.

Keywords: systematization of experiences; pedagogy; research methodologies

\section{RESUMO}

Este artigo apresenta a fundamentação da sistematização de experiências educativas (SEE) como uma metodologia que permite a visualização do que hegemonicamente permaneceu ausente e, portanto, procura a sua ressignificação e legitimação, aumentando assim a produção de conhecimento a partir da experiência das comunidades. Também, é definida a emergência da (SEE), bem como o seu percurso histórico, o estabelecimento das suas estratégias e ferramentas, bem como as etapas e as fases da aplicação desta metodologia. Finalmente, se sinala a partir da análise da experiência pedagógica a possibilidade de construir pedagogias Outras, como a pedagogia da conexão, produzidas a partir da experiência e em diálogo com as contribuições teórico-metodológicas apresentadas nesta pesquisa.

Palavras-chave: sistematização de experiências; pedagogia; metodologias de pesquisa 
En el documento se presenta la fundamentación la sistematización de Experiencias Educativas (sEE) como una metodología que permite la visibilización de lo que hegemónicamente ha permanecido ausente y de esta manera busca resignificarlo y legitimarlo, potenciando de este modo la producción de saberes desde la experiencia de las comunidades. También se definen la emergencia de la (SEE), así como su recorrido histórico, la constitución de sus estrategias y herramientas, así como los pasos y fases de la aplicación de dicha metodología. Por último, se plantean a partir de los análisis de la experiencia pedagógica la posibilidad de construcción de pedagogías Otras, como la pedagogía de la conexión, producidas desde la experiencia y en diálogo con los aportes teóricos-metodológicos presentados en esta investigación.

\section{Sistematización de experiencias educativas}

Frente al agotamiento de las epistemes eurocéntricas que proponen como única forma de conocimiento el logocentrismo cientificista, surgen en el último cuarto de siglo $\mathrm{xx}$, desde el campo de las ciencias sociales, perspectivas metodológicas en el orden de lo cualitativo, que permiten apreciar y reconocer un sinnúmero de conocimientos colectivos, tejidos en distintos territorios y tiempos. La sistematización de experiencias aparece como una de estas perspectivas, que responde a necesidades propias de nuestras latitudes; al respecto, Mejía (2009) enuncia:

Hablar de la sistematización es hablar de una práctica investigativa que se ha venido conformando en América Latina en la segunda mitad del siglo xx y los comienzos de este nuevo milenio. En ese sentido, hablamos de un proceso que nació unido a las dinámicas sociales, políticas y culturales que se desarrollaron en nuestra realidad y que llegaron a otras latitudes. (Mejía, 2009, p. 9).

De esta manera, emerge en América Latina la sistematización de experiencias como una posibilidad de desviarnos del modelo de desarrollo impuesto, ya que conforma un procedimiento para validar los saberes producidos desde comunidades de base, organizándolos y dotando de sentido sus experiencias para negociar, desde allí, el conocimiento teórico. Al mismo tiempo, ello genera "alternativas sociales, educativas, profesionales y culturales" (Jara, 2013, p. 156).

Torres y Mendoza (2013) mencionan que, a partir de ciertos cuestionamientos al sistema hegemónico, "surgieron diversas prácticas sociales inspiradas en la educación popular, en la teología de la liberación, en la comunicación popular, la psicología de la liberación y la investigación acción participativa" (p. 155); así, aparecieron metodologías descolonizadoras de discursos y prácticas, como la sistematización de experiencias, que reivindican procesos vernáculos investigativos.

Aunque -en un principio- esta metodología no fue concebida para sistematizar procesos educativos, a partir de su aparición y, hasta hoy, tanto escenarios populares, como educativos, han sido potenciados por la sistematización de experiencias, la cual ha fortalecido -al propio tiempo- los procesos sociales, porque empodera a sus protagonistas, y activa dinámicas identitarias generadas desde dichos procesos, por su capacidad reflexiva y crítica, como señala Leis (2006):

Tal vez porque se ha ido haciendo sentido común el valorar de manera impostergable la importancia de producir conocimientos a partir de nuestras experiencias, de rescatar aprendizajes desde nuestras prácticas, de no dejar pasar las innumerables lecciones que el quehacer cotidiano de la educación popular en nuestra América va dejando en quienes somos sujetos de estas experiencias y que, gracias a una reflexión crítica sobre ellas, nos permite convertimos en más protagonistas aún. (p. 3).

En el ámbito educativo, la sistematización de experiencias educativas (SEE), ha venido re-configurando proyectos educativos y quehaceres cotidianos, invitando a sus participantes a observarse, interpretarse y reconocerse como protagonistas de su propio proceso. Como apuesta metodológica de investigación, la SEE abre caminos hacia la producción de saberes desde las comunidades de base, es decir, grupos humanos que producen conocimiento al reflexionar sobre su práctica. Porque al hacerlo, reconocen y generan identidades emergentes dentro de dichos procesos, al mismo tiempo que fortalecen la visibilidad y empoderamiento de los actores sociales en sus acciones y las conciencias que tienen sobre ellas. Como enuncia Muñoz (2013), "la clave de la sistematización es reconocer y contribuir a formar como sujetos de 
conocimiento a los propios actores involucrados en la experiencia" (p. 24).

Desde este enfoque metodológico, el análisis y práctica de las experiencias es fundamental, porque es aquello que queda para siempre como lo actuado materialmente, aunque haya ocupado solo una fracción reducida de tiempo; es aquello que perdura y deja huella, el trazo de la acción en el mundo de la vida, inmanente de hecho y trascendente, a la vez. La experiencia está anclada en un tiempo y, a la vez, es una continuidad que, aunque invisible, recorre un camino y configura un espacio. Es, por tanto, una bisagra que conduce hacia la trasformación. En palabras de Larrosa (2009), en "la experiencia, el sujeto hace la experiencia de algo, pero sobre todo, hace la experiencia de la transformación" (p. 90).

En esta medida, son los sujetos de la transformación, los sujetos de la experiencia, quienes producen sentido y conocimiento desde la autocomprensión de sus procesos, como lo plantean Cendales y Torres (2006):

Toda sistematización, como modalidad colectiva de producción de sentidos, es siempre una experiencia inédita, dado que lo que se ponen en juego no son un conjunto de procedimientos y técnicas estandarizadas, sino las vivencias, sueños, visiones y opciones de individuos y grupos que la asumen como posibilidad de autocomprensión y transformación. (p. 29).

Así, la SEe permite visibilizar lugares Otros de producción del conocimiento, puesto que supone una negociación desde el análisis de los saberes emergentes de las prácticas con miras a la construcción de teorias. De acuerdo con Torres y Mendoza (2013), esta metodología puede ser entendida como una "práctica intencionada de generación de nuevo conocimiento sobre las prácticas educativas y sociales" (p. 165); en esa medida, se asume que la SEE puede demostrar que el pensamiento occidental merece ser cuestionado, revisado, trasgredido y transformado, de manera que el conocimiento sea orgánicamente pluriversal, un conocimiento de lugar, de contexto, en otras palabras, que tenga sus propios fundamentos.

Dicho cuestionamiento gira en torno a otras formas de conocimiento que no han sido reconocidas por la perspectiva occidental y occidentalizada del conocimiento, ni siquiera en el interior de las Ciencias
Sociales; se puede decir, entonces, que parte de problematizar que no han sido reconocidas aquellas formas de conocimiento que emergen de las prácticas de los sujetos. Por tanto, es necesario afirmar la sistematización de experiencias como un enfoque que permite potenciar pedagogias que descolonicen el conocimiento, desde el intercambio y la construcción colectiva de saberes, ya que plantea una serie de estrategias que recogen las prácticas y los discursos que surgen, justamente, en las luchas y la acción política e intencionada de los sujetos y las comunidades históricamente invisibilizadas, empoderándolos en el reconocimiento de los saberes producidos desde sus experiencias, de manera que se fortalezcan los procesos de des-aprendizaje, de-construcción y reconstrucción de lo impuesto y asumido a través del tiempo y se potencie la construcción colectiva de conocimiento.

Sin embargo, el camino de la sistematización no es fácil de emprender; se requiere de la voluntad suficiente y el interés de cada participante que, al comprender el empoderamiento que significa este proceso, asuma el reto y el desafío de cimentar estrategias que permitan reconstruir, analizar y resignificar la experiencia, como indica Mejía (2008): "la sistematización, al quedar delimitada por la especificidad de los contextos y la práctica, hace muy difícil replicar modelos o metodologías, ya que ellas requieren adecuaciones que le permitan a la riqueza de la práctica producir su saber propio" (p. 7).

En este sentido, si bien es cierto que se han hecho intentos por presentar algunas de las herramientas que mejores resultados han tenido en la SEE, "sin pretender ofrecer recetas o fórmulas absolutas" (Capó et al., 2010, p. 23), cada una de ellas se redefine desde diferentes perspectivas epistemológicas, según sea el caso. Al respecto, Torres y Mendoza (2013) dicen:

La sistematización de experiencias no es una metodología unitaria y homogénea. Desde su emergencia, han coexistido conflictivamente diferentes maneras de entenderla, asi como razones para justificarla y perspectivas epistemológicas desde las cuales fundamentarla; de igual forma, son múltiples las maneras de operativizarla metodológicamente. (p. 155).

Cada una de las herramientas metodológicas de la SEE busca, esencialmente, darle un orden a la práctica y 
jerarquizar las experiencias, de manera que soporten los conocimientos que de ellas emergen, con el fin de encontrar en la memoria corporeizada de las personas los elementos que permitan darle una altura conceptual a los procesos vividos. Así, el esfuerzo se encamina a darle rigor investigativo a acciones que, tal vez, en su momento, fueron cotidianas; por ello, los relatos, las historias de vida, las entrevistas, los grupos de discusión y la observación se entrecruzan para dar sustento epistemológico a procesos políticos, formativos y educativos.

Lo anterior supone que los mismos sujetos de la experiencia sean quienes puedan co-crear y construir las herramientas metodológicas que le dan voz a su proceso. En este caso particular, el proyecto Raíces, será por medio del relato que se construyan puentes y caminos en esa tarea de fundamentar epistemológicamente lo originado en el hacer.

Al respecto, Packer (2014) propone que el relato o como él lo enuncia, el análisis conversacional, es una forma de analizar la conversación ordinaria, enfocándose en la construcción práctica e interactiva de dichos intercambios cotidianos (p. 292), de manera que se incluyan las definiciones o descripciones que emergen desde la experiencia de los sujetos y las formas como dichos sujetos las comprenden.

El análisis conversacional se propone describir la conversación de una manera que se base en la manera en que las personas participantes la comprenden. Lo hace por medio de tratar cada locución como la muestra de una interpretación de la locución previa. (Packer, 2014, p. 294).

El relato es, entonces, esa herramienta metodológica de la sistematización de experiencias que me permite, desde la palabra, recordar, recuperar y compartir aquello construido en Raíces como se enuncia aquí:

Raíces es vivir, raices para mí ha sido caminar un camino de amor y transformación, ha sido tejer con mis amigos, con la profe Elisa, con las montañas, las cascadas, con la Madre Tierra, con la palabra que llena de vida cada paso. (D.R., Equipo de sistematización ${ }^{1}$ ).

El relato no divorcia la mente, los pensamientos, de lo sentido, ya que propone un acercamiento a la

1 D.R. y otros 6 estudiantes formaron parte del equipo de sistematización como se aclarará más adelante en este documento en el título de "Sistematización de la experiencia concreta". experiencia vivida desde la activación espontánea de la memoria, lo cual jerarquiza intuitivamente aquellos acontecimientos significativos y profundos del pasado, que perduran como una huella que, al pasar el tiempo, en vez de borrarse, se remarcan. Como afirman Cendales, Mariño y Posada (2004):

A través de los relatos, las personas van conjugando memoria y olvido, reinvenciones y proyecciones; van construyendo y reconstruyendo sentidos; entretejiendo sentimientos y datos; se van encontrando relaciones, van surgiendo preguntas sobre lo ocurrido y de ésta forma e inicia o se amplía el proceso analítico sobre la experiencia. (p. 25).

En relación con la experiencia, el relato y la narrativas se plantean, según González (2016), como "elemento organizador de la experiencia y fundamental para dar cuenta de la manera como se abordan las relaciones de significado en el sujeto" (p. 109), de manera que es a partir de lo que narramos que damos cuenta de cómo nos relacionamos, comprendemos y significamos la vida. "La experiencia solo puede existir en el acto de la narración cuando se transita del hablar sobre lo que pasa a relatar lo que nos pasa" (p. 109).

La resignificación de ese pasado es sorpresiva y misteriosa, tanto para el que relata como para el que escucha, quien, mientras lo hace, reordena y revive lo ya vivido, permitiendo que el relato mismo, en algunas ocasiones, se transforme en experiencia vivida. En relación con esto, Edilberto, un mayor muhysca, mencionaba en un círculo de palabra en Tenjo (Cundinamarca), al que asistí hace algunos años para pedir consejo sobre Raíces: "el oído más cercano a mi boca es el mío, por eso soy el primero en escuchar mis palabras, y descifrar desde ellas mi propio pensamiento". Así, el relato -que proviene de la oralidad de los actores de la experiencia, y a través del cual se identifican y obtienen los saberes que se lograron gracias a esta- se convierte en una herramienta que permite manifestar, en el marco de esta investigación, lo que desde el pensamiento ancestral se denomina palabra de vida.

Esta palabra de vida es palabra que nace en nosotros, que ha germinado en nuestra tierra fértil; tiene como sustento la acción en el mundo de la vida, pues "toda palabra, lejos de la acción, se convierte 
sencillamente en palabra vacia, en palabra prestada" (Hate Chuchavita, 2011, círculo de palabra, Sesquilé); de ahí la importancia del relato, como forma de transmitir lo que nace desde adentro, en la experiencia, y desde la autoobservación, ya que revitaliza y reconfigura un proceso de reafirmación. De esta manera, es a partir de la palabra tejida en colectivo y justificada en acciones también colectivas, como se apuesta, desde la SEE, por fortalecer una experiencia pedagógica decolonial.

Haciendo memoria, dicen los abuelos -aquellos a quienes la experiencia les ha dado la sabiduría y el conocimiento-, se organiza el pensamiento. Palabrear la vida para revisar lo que se hizo, lo que se sintió, lo que pasó con eso que se hizo y para saber en qué vamos; pues bien, el ejercicio de sistematización de Raíces nos concedió, justamente, la posibilidad de percibir, desde la práctica que, verdaderamente, la seE permite hacer memoria y con ello, empoderar, fortalecer, revisar y producir discursos y conocimientos, así como dar valor a lo que los sujetos aportamos al tejido social, tanto en lo individual, como en lo colectivo, con el fin de abonar a la constitución de una verdadera pertenencia.

La SEE me ha llevado, así, a tejer hilos sueltos, ubicar orígenes, descifrar (en las palabras y los gestos), eso que fundamenta la intuición investigativa del proyecto Raíces, reconocer lo que las montañas, las rocas, las aguas y el aire nos recuerdan, constantemente: la existencia de un conocimiento dormido acerca del orden de la vida y sus ciclos, permitiéndonos, desde el silencio $y$, también, desde la palabra, desde el caminar y el recorrer, desde el agradecer y el cuidar, sabernos parte de este planeta, de esta tierra madre y no dueños de ella.

Desde una perspectiva decolonial, este proceso de sistematización, al emerger de la propia experiencia de lugar, se presenta como una alternativa insurgente frente al antropocentrismo y el eurocentrismo propios del sistema de pensamiento occidental, de la misma manera que fomenta transformaciones en las visiones de mundo y descentración cultural.

La SEE se constituye como una herramienta metodológica de investigación que permite visibilizar Otras fuentes de información; en el caso de Raíces, los relatos de los protagonistas de la experiencia, en un diálogo de saberes con abuelas y abuelos humanos y no humanos, que trasmiten el conocimiento a partir del ejemplo, la palabra y la vida; pero también, los aportes de investigadores empíricos y profesionales del pensamiento ancestral en los territorios muhysqas, lo cual garantiza el develamiento de unos saberes, unos conocimientos Otros, generados por voces y pueblos silenciados, que los producen y legitiman.

En la perspectiva decolonial, la seE permitió demostrar que el proyecto Raíces brinda herramientas para reconocer el cuerpo y el sentir como lugar poderoso y certero de producción de conocimientos y que su sistematización da cuenta de la posibilidad de investigar, mediante una forma diferente de la convencional, a saber: logo-centrista, cientificista y eurocéntrica, propia del modelo-sistema epistemológico hegemónico.

La SEE nos arrojó a un pluriverso de posibilidades, en el que cada relato -o un fragmento de este- constituye un camino; la experiencia transformadora que nos ha concedido acercarnos a la SEE ha reconfigurado nuestra mirada de Raíces, reorientando su intención y redimensionando sus alcances.

Un proceso que inició sin otra intención que buscar escenarios de aprendizaje fuera de las paredes de la escuela trascendió en cada uno de nosotros, en la profundidad de nuestras geografías, nos convertimos en compañeros de caminos y rutas, de territorios interiores inexplorados que nos invitan a conectarnos por la belleza y majestuosidad de nuestra casa, de nuestro único hogar, la Tierra, así como de las memorias ancestrales que guarda en cada lugar el conocimiento de cuidarla y amarla.

\section{Sistematización de la experiencia concreta}

Los ejercicios de sistematización deben organizarse en un esquema que permita dar orden al trabajo y mantener la claridad de los propósitos; sin la intención de ofrecer un diseño único, algunos autores, basándose en experiencias y prácticas, proponen ordenar la sistematización por fases o momentos flexibles e interrelacionados, como lo plantean Capó et al. (2010):

[...] proponemos estructurar el desarrollo de este proceso en [...] momentos lógicos, secuenciales y complementarios entre sí, en el entendido de que los mismos forman 
parte de un sistema, por lo que guardan una relación de interdependencia entre ellos, pero también considerando que es un proceso flexible de ir y venir entre un momento y otro. (p. 23).

A continuación y siguiendo la propuesta anterior, presentamos las acciones desarrolladas en esta sistematización, que tejidas con algunos relatos recogidos que le dieron sentido al ejercicio; para esto, describiré el proceso realizado en los cuatro encuentros con el grupo sistematizador del proyecto Raices.

\section{Fase I: diseño y preparación de la sistematización}

\section{Conformación del equipo de sistematización}

Es un grupo de personas que se encarga de planear, organizar y evaluar el proceso de sistematización de la experiencia; su función consiste en establecer un plan de trabajo que permita organizar la información recuperada de la experiencia, así como también delimitar la sistematización, analizar los datos obtenidos, construir estrategias de activación de la memoria, entre otras.

En el caso de Raíces, el equipo estaba conformado por siete estudiantes que formaron parte del proceso desde el inicio y que se sintieron comprometidos con este, y por mí, que he sido lideresa del proyecto desde sus inicios. Ellos son:

» Mujeres: D.R. (15 años), M.C. (15 años), E.G. (15 años), M.P. (15 años) y Y.G. (16 años).

»Hombres: J.P. (15 años) y J.J. (16 años).

\section{Delimitación de la sistematización y plan}

de trabajo

Para esta parte del proceso, se realizó un taller en el que nos acercamos metodológicamente a la sistematización de experiencias, algo de su historia, planteamientos conceptuales y propuestas metodológicas. A partir de este momento, decidimos con el equipo delimitar la sistematización a algunas salidas pedagógicas desarrolladas en los primeros cuatro años del proyecto, es decir, en su primera fase. Tomamos esta decisión, porque sentimos que es, a partir del vivir, caminar y recorrer el territorio, que verdaderamente asumimos el proyecto, ya que alli, en el campo, los conceptos, nociones e ideas se hicieron experiencias a partir de la práctica. Las salidas pedagógicas fueron la columna vertebral de la experiencia.

El plan de trabajo propuesto por el equipo de sistematización quedó organizado en cinco encuentros: el primero nos permitió elaborar la reconstrucción histórica a partir de las salidas mencionadas anteriormente; en el segundo, se activó la memoria con respecto al pensamiento ancestral y al territorio; en el tercero, se llevaron a cabo entrevistas; en el cuarto, se organizó la información transcrita, y en el quinto, se socializó el proceso con los participantes del proyecto.

\section{Elección de herramientas metodológicas}

Las herramientas nos permitieron el proceso de indagación y sistematización de la información proporcionada por los protagonistas de Raíces respecto a su experiencia.

En primera medida, usamos la lectura audiovisual como una estrategia de activación de la memoria, a saber: fotografías y videos que nos ayudaron a recordar momentos de la experiencia, caracteristicas de los territorios; además, y lo que considero más relevante, las personas y las relaciones que tejimos con ellas. Algunas de ellas están, otras se han ido de la institución; forman parte de nuestros cambios y transformaciones, como lo expresa, en la siguiente frase, una de las participantes:

Esas personas que se fueron, que ya no están, son como las hojitas que lleva el viento, como la semillita que va a sembrar este proyecto en otras tierras, personas que se van pero que en parte se quedan. (M.C. Rejilla de información. Árbol).

Otra herramienta fundamental fue la entrevista semiestructurada, pues permitió fomentar un diálogo, indagar sobre las temáticas abordadas, las categorias o problematizaciones del proceso de sistematización, con apoyo de una guía de preguntas elaborada previamente; un ejemplo de esto es el siguiente fragmento de la entrevista realizada a D.R., en la que ella plantea su sentipensar sobre la categoría de territorio-cuerpo:

El territorio es ese camino que debemos caminar, todos, es rico salir a caminar, respirar aire puro, el territorio cuenta tantas experiencias que tienen nuestros ancestros, son 
tantas cosas bonitas que tú sabes que vivieron y si de verdad tu conexión es grande con el territorio; te conectas, te conectas, total, con ese territorio; sientes los seres, el ser del agua, el ser del árbol, de ese animal pequeño que está corriendo debajo de tus pies y ni siquiera lo notas. (D.R. Rejilla de información. Red semántica).

El relato, la historia ordenada de una serie de hechos o situaciones significativas que ocurrieron en un periodo, son anécdotas frente a la experiencia, las interacciones, sensaciones y momentos que permitieron a los sujetos conectarse y hacer de la acción una verdadera experiencia; con este recurso se reconstruyeron y recuperaron procesos propios de cada uno de los participantes, como manifestó otro de las integrantes del equipo sistematizador:

Para mí, esto ha sido un conocimiento, pues, que estaba perdido ¡no!, o sea nunca debemos olvidar, de dónde somos, de dónde venimos, de qué territorio somos. (J.P. Rejilla de información. Entrevista).

Los relatos se recogieron en una rejilla de información (tabla.1) y se obtuvieron de diferentes fuentes, fundamentalmente de los talleres de activación de la memoria.

Tabla 1. Rejilla de la información

Árbol de ideas

\begin{tabular}{|c|c|c|c|c|}
\hline Red semántica & Pensamiento & Territorin-cuerno & Cambios en la visión de & Cuidado de la vida \\
\hline Cartografías & ancestral & & mundo & \\
\hline
\end{tabular}

Fuente: elaboración propia.

Estas herramientas constituyeron una red semántica (figura 1) que recoge las nociones e ideas de lo que significaba el proyecto "Raíces"; la Red semántica buscaba indagar sobre las nociones, sentipensares y relaciones que concebíamos a partir del concepto de raíces, la idea era complementar los óvalos vacíos con los primeros pensamientos que venían a nuestra mente, posteriormente socializamos las redes semánticas, de alli salen los relatos ordenados en la rejilla.

Un árbol de ideas (figura 2) tenía como propósito indagar por las nociones, ideas y sentipensares sobre el concepto de ancestros y sobre el proceso del proyecto, de igual manera que con el ejercicio de la red semántica. Después de un tiempo prudencial socializamos nuestros árboles, de alli se recuperaron los relatos ordenados en la rejilla de información.

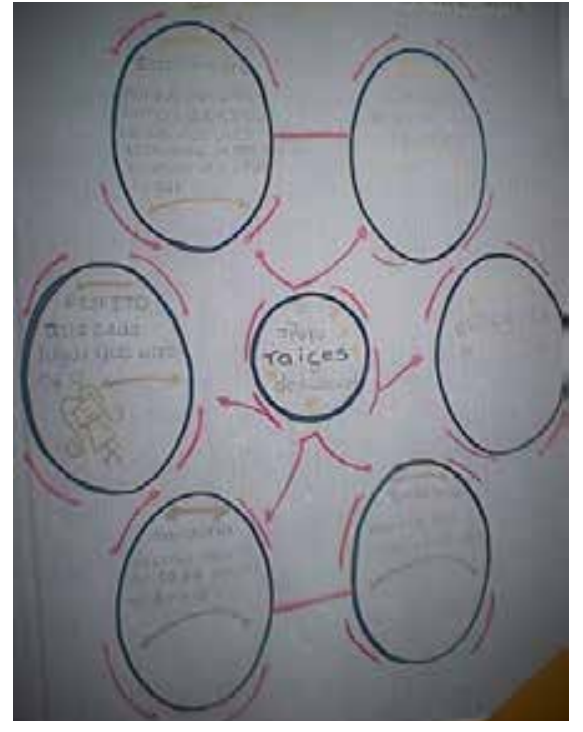

Figura 1. Red Semántica de D.R.

Fuente: elaboración propia. 


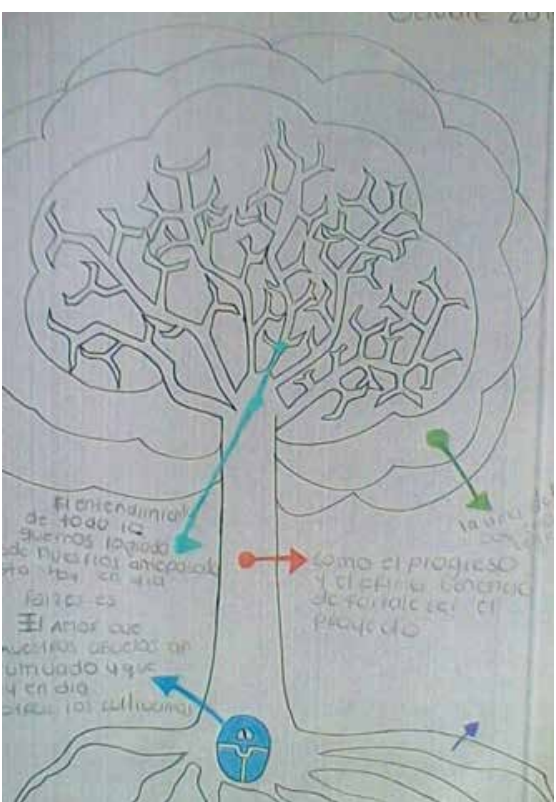

Figura 2. Árbol de ideas. E.G.

Fuente: elaboración propia.

Y, por último, la cartografía social nos ayudó a reconstruir históricamente el proceso, y le otorgó a los lugares un orden de importancia y activando la memoria de la experiencia, así como la trascendencia de recorrer el territorio y la huella que queda de la experiencia vivida. El trabajo realizado con la cartografía social fue determinar el orden de importancia de los territorios elegidos para la sistematización, como se puede ver en las figuras 3 y 4, cada uno de nosotros dimos una jerarquización (por medio de números) a los lugares visitados. En la socialización íbamos presentando cada lugar según nuestro propio orden, de alli se recogieron los relatos que parecen condensados en la rejilla de información.

Cada uno trae demasiadas cosas muy buenas que te sirven para tu vida, te aportan demasiadas cosas y pues de cierta forma cada salida cuando caminamos, cuando estamos en ese momento en silencio en el que cada uno da su ofrenda a la madre tierra, entrega su semilla a la tierra y pues es una forma bonita de decir que realmente estas conectada con la vida. (D.R. Rejilla de información. Entrevista).

La rejilla nos permitió la recolección de la información, mediante citas o fragmentos de los relatos

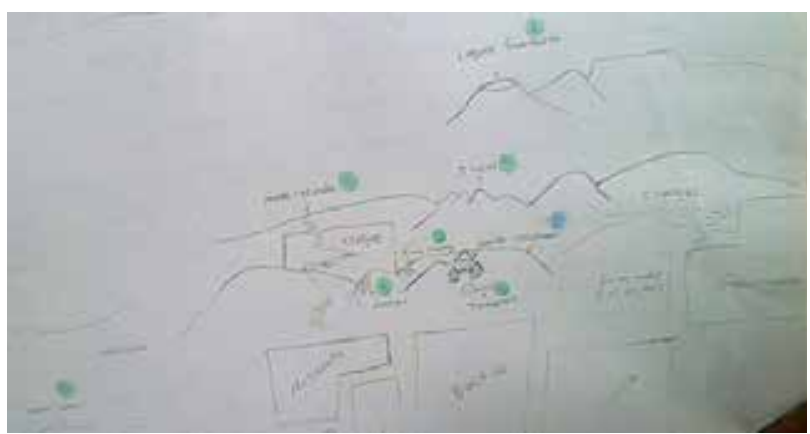

Fgura 3. Cartografía de J.J.

Fuente: elaboración propia.

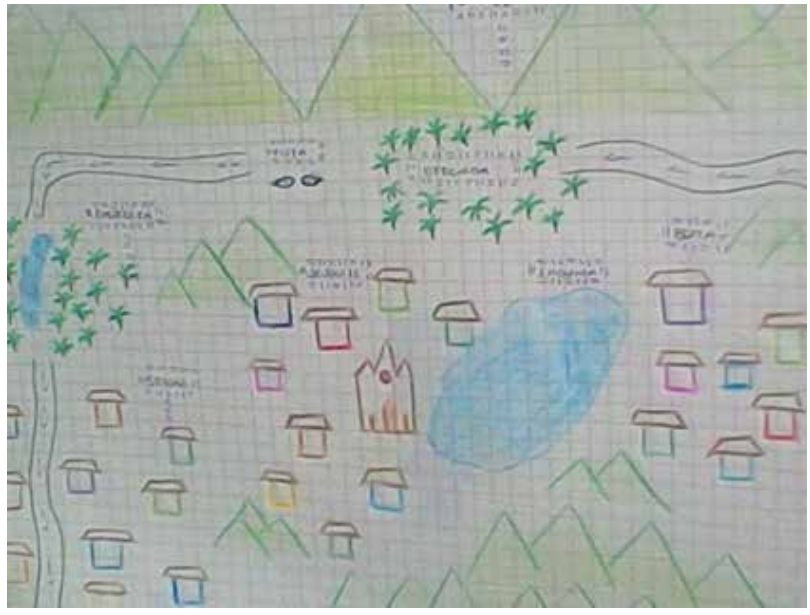

Figura 4. Cartografía M.C.

Fuente: elaboración propia.

que sirvieron de soporte para sintetizar y organizar los datos, según las categorías de sistematización de pensamiento ancestral y territorio-cuerpo; no obstante, durante la organización de la información y su análisis emergieron dos categorías más, a saber, cambios de la visión del mundo y cuidado de la vida.

\section{Fase 2: sistematización del proyecto Raíces}

\section{Reconstrucción histórica}

La reconstrucción histórica de Raíces se elabora, en un primer momento, a partir del material visual que los participantes del proyecto fuimos recogiendo de las salidas pedagógicas, organizándolas 
cronológicamente. En un segundo momento, mediante la elaboración de una cartografía social (figura 5) de los territorios recorridos, se buscó que cada uno de nosotros, individualmente, pero también como equipo sistematizador, le encontrara un sentido a cada territorio desde lo vivido.

\section{Profundización temática y elaboración del documento}

En esta parte, se definieron y analizaron elementos emergentes de la sistematización, dándole cuerpo al diálogo de saberes, producto de la experiencia del proyecto Raíces y las referencias conceptuales de la pedagogía decolonial, así como las metodologías de la sistematización de experiencias.

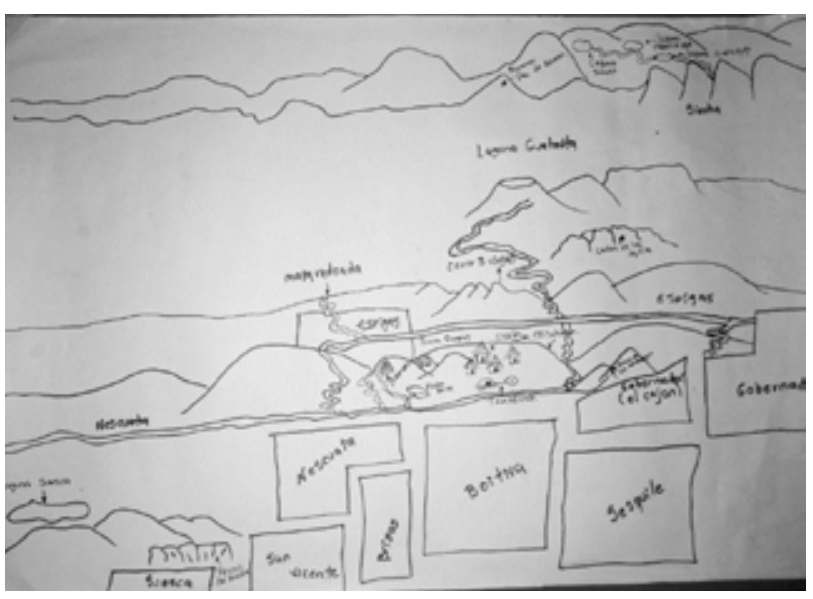

Figura 5. Cartografía base para el taller de reconstrucción histórica

Fuente: elaboración propia.

\section{Fase 3: socialización y retroalimentación}

La socialización de la sistematización de experiencias la hicimos en una salida al cañón de Las Águilas, localizado en la vereda El Hato; allí nos sentamos a compartir la palabra sobre lo que habíamos descubierto de nuestro proyecto, cómo podíamos encaminarlo de ahora en adelante y sobre otras acciones que emprenderíamos.
Trayectorias del proyecto: nuestra historia

La reconstrucción histórica será presentada en orden cronológico desde 2011, cuando inicia la primera fase del proyecto, hasta 2014, fecha de la finalización de la misma, en un texto basado en las relatorias que se realizaron en la sesión de reconstrucción histórica, en la mayoria de los casos están transcritas tal como se escribieron en dicha sesión y están apoyadas por algunas citas de los participantes en el ejercicio de cartografía social.

Es importante aclarar en este punto que las salidas que aparecen en esta reconstrucción fueron escogidas, de entre muchas otras, según el grado de importancia que les dimos colectivamente; por este motivo, en algunas partes del documento, se hace referencia a ciertas salidas que no fueron parte de la reconstrucción como tal. De la misma manera, se nombrarán someramente algunos talleres o acciones desarrollados en el marco del proyecto, en los que decidimos no profundizar.

Por último, conviene aclarar que estas relatorias ordenan lo que fuimos recogiendo en la sesión; la redacción estuvo a mi cargo, pero cuando el relato hace referencia a mi, la hice en tercera persona puesto que, así, recogía la voz de los participantes del equipo sistematizador. Ha sido organizada en orden cronológico, por año y cada uno de ellos lleva un nombre en lengua muhyscubum, respondiendo a las disposiciones del equipo sistematizador.

Esta reconstrucción inicia con la siguiente reflexión, que recoge en gran medida la disposición y actitud que hicieron que cada una de las caminatas 0 salidas se convirtieran en una experiencia nutritiva y rica en aprendizajes.

Todas la salidas han sido importantes porque en cada una de ellas aprendemos algo nuevo, en cada una de ellas obtenemos experiencias que nutren cada vez más nuestras vidas, en cada una de ellas voy con la misma actitud, si, esa actitud de seguir aprendiendo; y la mejor manera de aprender es poner todo mi interés en este camino que de cierta forma hemos ido construyendo a través de conocimiento, risas, abrazos, unión y lo más importante, amor. (D.R. Taller de reconstrucción histórica). 
2011. ATA2

Cabildo indigena Muhysqa de Sesquilé "Chuta fa aba. Los hijos del maíz". Sesquilé (Cundinamarca)

La primera salida que hicimos con el grupo Raíces fue a comienzos de 2011; empezábamos a conocernos como grupo, éramos veintiocho con la profe, y la desarrollamos luego de acercarnos por medio de algunos de talleres al pensamiento ancestral. En ellos, se habian tratado temas: mitos, usos y costumbres de la cultura muhysqa; hicimos todo el recorrido caminando, nos acompañaban [los mayores] Juan Romero y Oscar Chautá, quienes desde entonces nos han guiado en la mayoria de las caminatas.

Llegamos al cabildo y conocimos las casas ceremoniales, la cuca que tienen alli, en el territorio que no es natural, ellos la fabricaron, así como el cusmuy y el temazcal; hicimos los recorridos por el mirador de aves y el Camino del Silencio; antes de irnos, jugamos con arcilla en el taller de cerámica de la comunidad.

El cabildo, donde fuimos por primera vez pues allí comenzó una transformación ¿no? Comenzaron a interactuar saberes de algo que yo no me imaginaba que existía; la verdad, no tenía conocimiento de que algo tan bonito está tan escondidito [risas]. (M.C. Taller de Reconstrucción histórica).

Laguna sagrada del cacique Guatavita. Sesquilé (Cundinamarca)

En este recorrido, iniciamos con las ofrendas; ibamos con Oscar. Una ruta nos llevó y nos recogió. En el chunzuá de la entrada hicimos danzas en espiral, para activar nuestra parte femenina, para que la laguna pudiera enseñarnos sobre el cuidado de la vida, sobre la abundancia de lo femenino; caminamos hasta llegar a la parte alta y alli, nos sentamos formando una circunferencia. La profe Elisa nos dio maíz para dejar como ofrenda en la laguna, nos quedamos en silencio un rato y escuchamos que el viento cantaba. Después de eso, la profe habló de ese canto del viento; nos decía que los abuelos antes tenían la capacidad de interpretar ese sonido como un mensaje y también de comunicarse con los elementos, que los

2 Primer número muhysqa tiene relación con el agua, la imagen es la rana que significa, en la dimensión temporal de los calendarios agrícolas, el inicio de la siembra. abuelos eran muy sabios porque podian estar en silencio por mucho tiempo; de ahí en adelante, íbamos a permanecer en silencio por un rato, siempre que subiéramos al monte.

Por ejemplo, las lagunas son la representación de lo espiritual femenino, ellas son lugares donde los ancestros iban a pedir consejo de mujer, de amor, de cuidado. (E.G Taller de reconstrucción histórica).

\section{Cascada sagrada La Chorrera. Sesquilé}

(Cundinamarca)

Esta salida a La Chorrera la subimos con tres acompañantes del cabildo, Oscar, Juan y Yenny, quienes nos llevaron hasta la entrada de los Vera, y ahi empezamos a subir al rancho. De ahi, un grupo se iba a La Chorrera y otro se quedaba jugando a correr por la tierra con unos costales. En el primer grupo, se fue la profe con Oscar; esa salida fue muy especial porque, a pesar de que era un poco difícil, la profe no la canceló y subió hasta la última chorrera con nosotros y con ocho meses de embarazo; todos le gritábamos que era una guerrera, cuando llegó a la casa del árbol, donde nos encontramos al final,

[...] yo iba subiendo y pensaba cada vez más arriba que no tenía ni idea de cómo me iba a bajar, especialmente en las rocas que teniamos que abrazar y yo con esa barrigota, itenaz! Pero sí me atemorizaba, metía la pata, porque ustedes, todo el tiempo, me andaban monitoreando.

Estando en La Chorrera, como habíamos hablado antes de iniciar el recorrido, quedamos que alli arriba no se podía hablar duro y siempre con mucho respeto, al llegar nos subimos a unas piedras, para mojarnos y $\mathrm{V}$. y Mono se pusieron a jugar, hasta que Mono salió volando "la profe fue la primera que pegó un grito; yo creo que despertó a todos lo mohanes"; se pegó duro, pero se levantó, tenía una pequeña heridita en la frente, Oscar y la profe le pusieron tihiky para que le frenara la sangre. Esta vez, la ofrenda fue en la parte de abajo antes de empezar la escalada, con algodón y canciones que habiamos aprendido en talleres del proyecto en el colegio.

La Chorrera [...] es una de las salidas que más me ha generado miedo porque tuvimos que escalar unas piedritas que eran un poco lisas porque esos días había como 
llovido entonces tenía miedo, mucho miedo [...]. Me ayudó a superarlo y pues, a lo último, valió la pena haber subido y haber tenido tanto miedo porque en realidad ver esa fluidez con la que baja esa agua y cómo impacta en las piedras, también es muy bonito. (M.C. Taller de Reconstrucción histórica).

\section{2. $\mathrm{BOSA}^{3}$}

Rocas y cuevas. Suesca (Cundinamarca)

La salida a las rocas fue especial; primero, porque llevábamos mucho sin salir del colegio, porque la profe había estado con el parto de su bebé y casi no vuelve al colegio; ese año, fueron más los talleres en el cole, habíamos hecho taller de tejido, de danza y canto y de lengua; y segundo, porque aunque muchos ya conocíamos ese lugar, ese día descubrimos que de verdad, como hablamos, los territorios tienen tesoros ocultos, que solo se hacen vivibles cuando queremos mirarlos. Ese día, llegamos directo a la cueva, o cuca; éramos veintidós con la profe, "estaba muy lluvioso por esa época y en la cueva se habia hecho un pozo, eso sí me daba mucho miedo, casi me muero del miedo, pero después de estar adentro ya no podía retroceder porque yo era una de las primeras". Adentro de la cueva, nos quedamos en silencio, "para mí, ese ratico fue eterno, las gotas caían en el pozo tenían como un ritmo, una canción".

Recogimos algo de basura de la cueva y sus alrededores y nos subimos a la roca de los pictogramas. Alli, Oscar nos contó historias, sobre los abuelos que habitaban alli, desde alli también se ve Güita, que la llaman "Nido de Brujas", y Oscar también nos habló de las fuchas muhysqas. Seguimos subiendo por detrás de esa abuela roca, y llegamos a la parte de arriba, donde hicimos pagamento; ese día, cada uno de nosotros Ilevábamos un escrito en una hojita de eucalipto o en trozo de madera. Esa fue la ofrenda con cantos también, "y soplamos como los abuelos para el lado de las Tres Viejas, pidiendo para que nos hiciera buen clima cuando fuéramos para allá".

Las cuevas de Suesca. Ahi, quisiera recordar a Oscar; él nos contaba muchas historias y de los mitos de creación

\footnotetext{
3 Segundo número muhysqa tiene relación con un cercado que defiende la siembra de animales dañinos; su imagen representativa es una nariz con dos ventanas abiertas y el disco lunar.
}

de Piracá, de Huitaca, y siempre nos estaba contando historias de los mohanes, de los espiritus que están en los territorios y, pues, obviamente, también en las rocas el silencio y el frio de la cueva... y fue bonito entrar y hacer el ejercicio de escuchar ese silencio ahi en las rocas, de escuchar el silencio... que, digamos. Es algo que uno no está acostumbrado hacer. (Elisabet Rodríguez Vargas. Taller de Reconstrucción histórica).

\section{Cerro de Las Tres Viejas, Sesquilé}

(Cundinamarca)

Las Tres Viejas o Tres Cuchas, le Ilamamos nosotros, "porque cucha es un muisquismo, es decir, palabras que aún están en nuestras costumbres, pero que son muy antiguas; cucha se refiere a una persona que tiene sabiduria, porque es mayor, la experiencia le da la sabiduría". Esta salida la acompañó Juan; para este tiempo, él ya no estaba en la comunidad y fuimos con la Escuela de Caminantes Kiqua Naskua; subimos hasta Las Espigas, en las rutas del transporte rural, Cootranscovadonga, y empezamos a subir después de la escuela, "antes de esta salida, habíamos tenido un taller de cosmovisión en donde habíamos aprendido sobre la relación de los calendarios agrícolas, lunares y solares"; ese dia, Juan nos mostró algunas piedras desde donde los abuelos podian interpretar el pasar de los días y entender los movimientos del cosmos; también recordamos ese día una de las historias de la formación de las Tres Cuchas, que nos había contado Oscar, que a su vez había escuchado de Mamanché:

Mucho tiempo atrás, unos abuelos muy sabios que vivian hacia el norte, soñaron con mucho fuego de guerra aquí, por estos territorios, y por eso, enviaron un joven para que trajera el mensaje de paz y de armonía. El joven corrió y corrió, atravesando montañas, cordilleras, valles y planicies. Como los abuelos no habian podido darle bien las indicaciones del lugar, porque no es fácil ubicarse en los sueños, el joven debía detenerse por momentos a sentir si era alli donde debía dejar el mensaje; por fin, llegó a nuestro territorio y aunque tenía sus dudas supo que era aqui; sin embargo, al ver que no había peligro cerca, quiso dormir un poco, antes de bajar de los cerros y hablar con los lideres de la comunidad. Asi lo hizo; cuando el joven despertó, todo estaba en Ilamas y ya no servia el mensaje que traía, decidió entregarse alli a la tierra, para que, al pasar el tiempo, todo aquel que quisiera recordar la sabiduría de sus ancestros fuera a buscarlo a la cabeza. 
Por eso, Las Tres Cuchas tienen forma de cabeza y, por eso, el municipio se llama Sesquilé, que en muhysqubum, se dice sisqiiieé, sisqi que significa "cabeza", y el sufijo ié significa "camino". Sesquilé significa "camino a la cabeza". Ya estando arriba, hicimos la ofrenda, todos pudimos decir nuestra palabra, especialmente la profe, M., G. y J.

[...] la salida a Las Tres Viejas [...] en este [...] recorrido [...] quedé muy impresionada: más que presenciar muchas cositas, desde cierta altura pudimos en realidad ver que la naturaleza es perfecta, digo la perfección de las montañas y la pureza que guarda Sesquilé en su interior, que todo esto debemos proteger. (M.C. Taller de reconstrucción histórica).

\section{3. $\mathrm{MIQA}^{4}$}

Laguna de Suesca. Suesca (Cundinamarca)

A la laguna de Suesca fuimos con otra gente: Fabián, que venía de Tenjo y traía música para compartir, él sabía del idioma muhysqa y nos compartió mucha información que había encontrado, hablando con los campesinos más viejitos de su municipio, y con Julián, un joven que venía a enseñarnos sobre las pictografias muhysqas. Tuvimos tres talleres con ellos y luego fuimos a la laguna, "cuando llegamos, notamos que la laguna estaba contaminada, que nadie iba hacia rato a agradecer por el agua y que la laguna estaba triste". Hicimos ofrenda de palabra, la profe nos decía que así como estaba esa agüita, a veces nos poníamos nosotros también, que cómo era de importante ponerle cuidado a nuestra agüitas, limpiarnos no solo por fuera el cuerpo, sino adentro, nuestros pensamientos, que esa era una tarea de todos los días, que si uno se emperezaba y dejaba de darse cuenta, cómo era que estaba pensando, cuando se daba cuenta, ya estaba como la laguna, todo contaminado. Como la laguna está triste, nos pusimos a cantar, a ver si los guardianes espirituales del territorio se animaban a volver, "cantamos muchas canciones hasta que hicimos llover, hasta las hijas de la profe cantaban. Cuando nos dimos cuenta, estábamos muy felices y jugamos a caballito y corrimos y reímos mucho". A pesar de que al principio nos

4 Tercer número muhysqa, significa lo diferente, lo escogido. La imagen que lo representa es de dos ojos y el disco lunar. dio mucha tristeza, al final fue una salida donde estuvimos muy felices.

La laguna de Suesca, sé que es un lugar que -como decía J.- es un sitio que está contaminado, pero también guarda una pureza en su interior, pues las lagunas representan lo femenino y lo femenino trae en si trae algo que opaca todo lo malo. (M.C. Taller de reconstrucción histórica).

Así como en la laguna de Suesca sentíamos el agua triste, como sentíamos esa vitalidad en otros territorios también, las cuevas nos cuentan con el silencio, el frío en Siecha, nos habla en formas bien especiales; entonces, siento que esos son los ancestros y muchos otros pero esos son los ancestros que encontramos en Raices. (J.P. Taller de Reconstrucción histórica).

\section{Cerro Chibchacun y Covadonga}

Esa salida la acompañó Juan; subimos por El Cajón y estaba lloviendo mucho, tanto que El Cajón estaba inundado, ya íbamos empapados media hora después de iniciar la caminata. Llovió casi todo el camino, el único momento despejado fue en lo alto de Covadonga [donde] pudimos apreciar el paisaje y tomar refrigerio; ese día fue especial porque después de subir Covadonga y hacer la ofrenda, Juan nos guio por un atajo, para llegar a Chibchacun; fue un camino un poco peligroso, porque si no estábamos concentrados, podiamos resbalarnos por lo mojados que estábamos. Íbamos por el filo de la montaña, tocaba ayudarnos entre todos, para no lastimarnos; tomamos el atajo desde la cima de Chibchacun hasta llegar al camino de La Chorrera y allá terminamos de mojarnos, quitándonos un poco el barro en el pozo de la entrada, "creo que esa es una de las salidas en las que más me he reído, y caído también" ,"lo más interesante fue que no había camino, que lo íbamos abriendo a medida que avanzábamos; Juan nos decía después que asi tocaba, a veces, en la vida, tocaba hacer el camino", nos caímos y nos embarramos... estábamos muy sucios cuando llegamos al pueblo, pero felices".

Es chévere caminar, sudar, esforzarse, no querer más, porque al final uno sabe que va a estar feliz de haber subido la montaña y haber podido ver un poco la inmensidad de la tierra. (J.J. Taller de Reconstrucción histórica). 


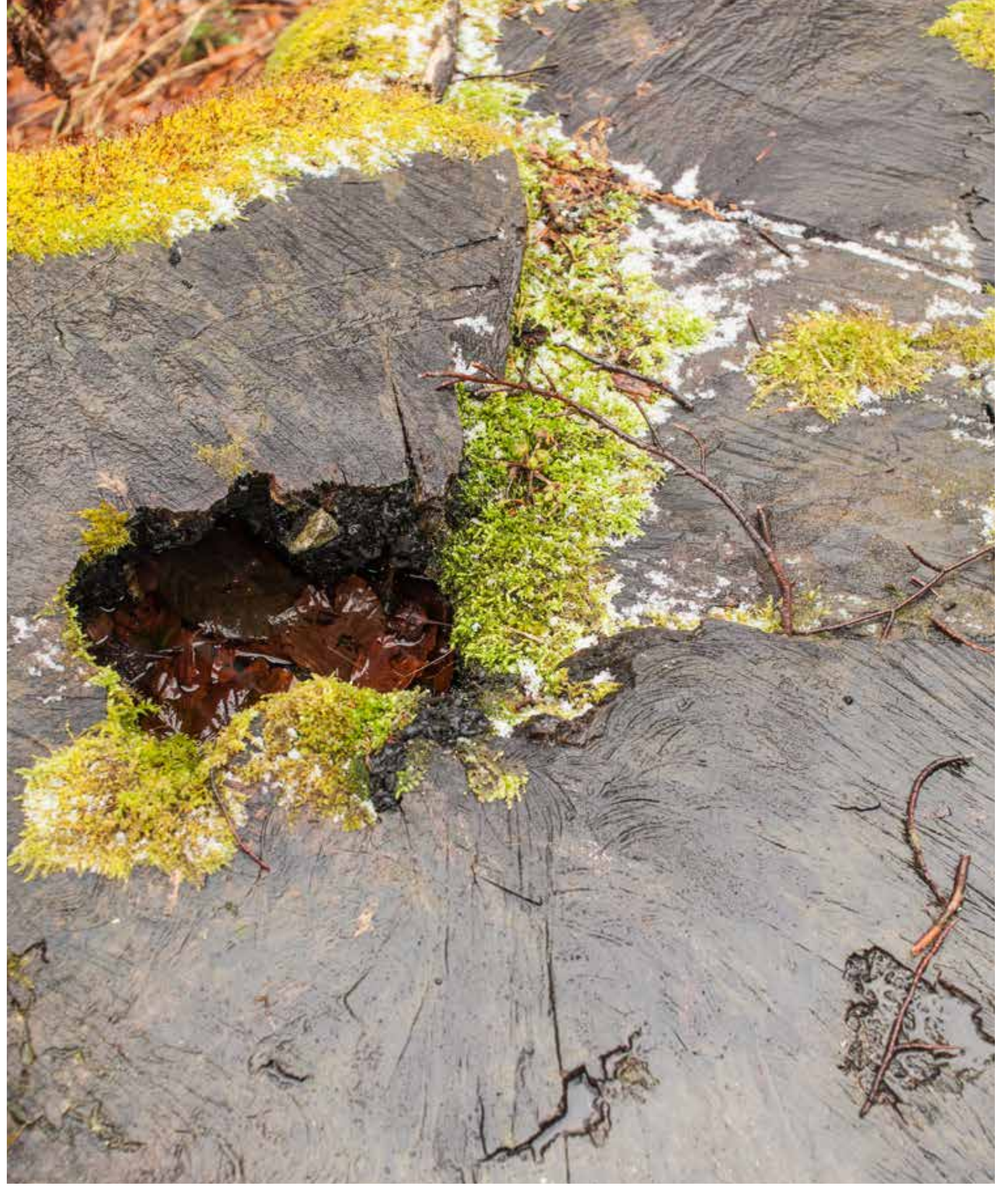

\section{$\Delta$ \\ Autora: Ileana Álvarez Reyes \\ Título: Atajos \\ Lugar: Chifk, Stara planina, Bulgaria}


2014. MUHYSCA5

Resguardo indígena. Finca Mamanche. Campamento

Al campamento fuimos 27 personas; nos acompañaban ese día Camilo, Oscar y Yeison. La idea principal de esa salida era elaborar un herbario virtual, y pues se vincularon al proyecto otras asignaturas, por ejemplo, educación física, biología y química, tecnología, español, ética y religión, y la entrega del herbario la evaluarían todos los docentes. Fue un viernes, llegamos a las 11 de la mañana a la Casa del Árbol; organizamos las carpas y nos fuimos para La Chorrera; allí, tomamos fotos de la mazorca de agua, que [sirve] para las enfermedades respiratorias, de la arracachilla que es para subir defensas, del cordoncillo para los hongos y las alergias. Hicimos pagamento y nos devolvimos. Nos organizamos para preparar alimento, comimos y luego fuimos al observatorio, a encender un fuego, cantamos hasta tarde y luego salimos a una actividad que era quedarnos en el silencio y en la oscuridad, eso fue muy especial para muchos de nosotros.

Cuando fuimos al cerro del camping, cerro Chibchacun creo, no, no tanto como fue el recorrido y lo del camping, sino que hubo un momento en el que hicimos un ejercicio y hubo una conexión que sentí con mi mami. (M.C. Taller de Reconstrucción histórica).

Al otro día, madrugamos a hacer otro recorrido y ahi vimos y fotografiamos otras plantas, el chite para limpiezas de hígado; la uva camarona y la vira vira, para problemas de riñón; el romero de monte, para el cabello y fortalecer el cerebro; la ortiga, para oxigenar la sangre. Al terminar el recorrido, recogimos todo, comimos y nos sentamos a compartir palabra, la pasamos muy chévere ese día.

\section{Matarredonda}

Esta salida la acompañó Juan con un compañero de Escuela de Caminantes, llamado Edison; la subida por Espigas fue tenaz, "subimos muy rápido y el sol estaba tan fuerte que nos dio la pálida" (nos mareamos). "Matarredonda es un lugar muy misterioso, muy

5 Cuarto número muhysqa significa "lo que es negro", tiene relación con la llegada de una nube de tempestad, la imagen es de unos ojos cerrados. mágico, está lleno de cuevas y huecos que parecieran sin fin"; ese día hicimos un proceso con lo masculino y lo femenino, hicimos pagamento por aparte y después nos unimos nuevamente para compartir [la] palabra, dejamos una figura hecha con semillas en la piedra más grande y "ese día le cantamos mucho a las nubes, para que lloviera porque lleva mucho tiempo calentando duro, no sé si fue eso, pero me gusta pensar que por los cantos, a los dos días empezó a llover arriba en la montaña, en los páramos".

En Matarredonda, hubo un ejercicio; como con los hombres, Juan estaba acompañándolos y yo estaba con las chicas, en ese momento y yo sentí como que las dos fuerzas se habian estado como equilibrando en el proceso. A mí me gustó mucho ese día, por eso y pues porque el lugar, además es bien especial, como las cuevas...esos lugares... como tan misteriosos ese misterio de ese lugar. (Elisabet Rodríguez Vargas. Taller de Reconstrucción histórica).

\section{Lagunas de Siecha}

A Siecha fuimos solo 19 participantes; nos acompañó Juan, "fue muy bello ver cómo, en las montañas, las plantas se encargan de hacer nacer los ríos, eso es increible y maravilloso", visitamos las tres lagunas sagradas; en la primera, los hombres pusieron palabra, agradecieron por sus padres, por su fuerza y su equilibrio, Juan, Edwin y Jaime entonaron unos cantos y ordenaron la ofrenda; en la segunda laguna, las mujeres hicieron la ofrenda, Elisabet, Maria y Geraldine pusieron palabra y cantaron, agradecieron por las madres y por la madre ancestral que nos llena de amor y alimento y nos da un hogar en la tercera laguna, hicimos todos ofrenda y compartimos alimento.

"La profe ordenó la ofrenda y fue muy bello, muy triste un poco, porque ella quiso agradecer alli por la vida y la muerte, había entre nosotros una compañera que ya no estudiaba en el colegio, Leidy. La profe ya nos había comentado que ella había tenido un hijita, que se había muerto de una semana de nacida y que Leidy estaba muy mal, muy triste... entonces, nos pidió que le diéramos todo nuestro amor y nuestra fuerza. Entonces, la profe habló de la muerte, de lo bella que era la muerte, porque nos permitía amar con más fuerza la vida, lloramos mucho y ella decía que las lágrimas purificaban nuestro ser, que llorar era 
también una medicina; al final, nos abrazamos todos un buen rato". "Lo más duro fue escuchar, hablar y llorar a Leidy, ahi en esa ofrenda recordamos a todos nuestros muertos, cada uno de nosotros le agradecimos por sus enseñanzas en vida". "La neblina iba y venía, lo más impresionante era que cuando bajaba la neblina, yo sentía que nos abrigaba".

Escogi Siecha como la salida más importante, me parecieron muy interesantes las montañas y todo el territorio, me dejó impresionado ese territorio ancestral. (J.P. Taller de reconstrucción histórica).

Las lagunas de Siecha ha sido una de las últimas salidas, es un lugar increíble; alli podemos encontrar una armonía que uno en realidad lo hace sentir como lleno, como bien con uno mismo, esa transparencia que tiene ese agua, que aunque hace mucho frío, como que congela todos los males del corazón; entonces, es muy bonito. (M.C. Taller de reconstrucción histórica).

Las salidas permitieron a Raíces acercarse al conocimiento sobre nuestros ancestros, sobre la importancia de los territorios y la transformación que, de alguna manera, ellos generaron en los integrantes del proyecto, en sus vidas y en su visión de mundo, como podemos observar en la siguiente cita:

Dentro de las salidas tejemos conocimiento, construimos valores, sembramos unión; este proyecto involucró de una manera tremenda mi vida, a través de él tomo mi ser y el ser de los demás como lo más puro de la vida. En las salidas dejamos a un lado lo material y empezamos a ver la importancia de la vida misma, la esencia consta de la luz que estés dispuesto a darle. Jeje. Bueno, qué bonito. (D.R. Taller de reconstrucción histórica).

\section{Elementos para una pedagogía decolonial}

A partir de la sistematización de la experiencia de Raices, especialmente de sus relatos y entrevistas, se reconoce que el equipo que forma parte del proceso, además de haber interiorizado la experiencia y entablado un diálogo de saberes que permite la construcción de conocimientos desde la misma, dio valor a sus reflexiones, pensares y sentires en relación con los territorios habitados pero también en relación con sus propias geografias interiores.
En esta medida, Raices explora la experiencia vital para construir memoria colectiva, potencia la voz de los participantes y permite abordar los temas del pensamiento ancestral desde el reconocimiento de saberes propios y del sentir el territorio y el cuerpo, como elementos fundamentales en la producción de conocimientos Otros.

Los elementos que autopoyéticamente responden a una experiencia de pedagogía decolonial se categorizaron en: pensamiento ancestral, territorio-cuerpo, cambios en la visión de mundo y cuidado de la vida.

» Pensamiento ancestral. El pensamiento ancestral se presenta como referente teórico, conceptual y metodológico de la propuesta pedagógica, de manera que transgrede la perspectiva dominante de la educación en la escuela. Sin embargo, este no se plantea como único camino posible puesto que dialoga con las ideas, intenciones, discursos y prácticas de sus participantes. Lo anterior sugiere una ecología de saberes en la escuela, lo que fomenta unas acciones y reflexiones desde la interculturalidad y la decolonialidad. Se legitiman también desde el pensamiento ancestral fuentes Otras y conocimientos que habian sido subalternizados desde la escuela agenciando perspectivas Otras de saberes situados histórica y espacialmente.

Territorio-cuerpo. El concepto de territorio se amplía, dando cabida a otras posibilidades de sentido como las que suponen los pueblos andinos en esa relación profunda de la tierra -como madre que brinda hogar y sustento- y los seres que la habitamos, reconociendo que cada especie, cada ser ocupa un lugar importante en el tejido de la vida, así como la importancia de buscar el equilibrio y la armonía. Desde la perspectiva del pensamiento ancestral, la tierra está viva, de esta manera se trascienden los conceptos positivistas que desde la razón simplifican la tierra a un recurso usufructuable. Por último, plantea una relación de compenetración en la que se cuestiona el individualismo fomentando la conexión con la madre tierra, y con todo lo que existe. 

más allá de razonarla, sentipensar como la acción de encontrar en el sentir una fuente de conocimiento susceptible de ser filosofado, pensado, examinado. Asumir la corresponsabilidad en la construcción de nuestra realidad y plantear desde esa conciencia la potencia de buscar en nuestra historia las claves que nos permitirán comprendernos como sujetos y como pueblos. Cuestionar lo establecido como verdadero o como natural, de manera que se abra el abanico de posibilidades de sentido para comprender nuestras dimensiones sociales, políticas y epistémicas. Transformar así nuestras posiciones politicas y éticas. Se plantea una historia antes historia hegemónica, una transgresión del tiempo lineal.

» Cuidar la vida. Cuidar la vida como premisa y principio, basándonos en la compenetración en la conexión con la vida. Poner la vida en el centro como posibilidad ética y política, que transgreda el pensamiento competitivo instaurado en la escuela y en la sociedad, de manera que se cuestione el sentido de la vida que nos invita a poner en el centro el mercado, el dinero o la comodidad. Cuidar la vida significa cuidarnos a nosotros mismos, al otro y todo lo que existe, comprendiendo que al contrario de lo que se enseña en la escuela convencional, todo está tejido y relacionado.

Comprendiendo la importancia de ese compromiso inexcusable que tengo como maestra de iniciar procesos de emancipación y descolonización, quedan pocas certezas al iniciar esta apuesta por el des-aprendizaje, por una lectura sin verdades inacabadas, inconclusas y cambiantes. El gran desafío que involucra el hablar de pedagogías Otras es prometedor y provocativo.

En ese sentido, la pedagogía de la conexión emerge como resultado de la observación de la acciones pedagógicas ordenadas por medio de esta sistematización de experiencias; tiene sus cimientos en el cuerpo de lo que conocemos hoy como pedagogías decoloniales -que se encuentran en construcción, es decir que están inacabadas, inconclusas- y se ordena en tres direcciones, asi:
» Conexión con uno mismo. Fundamentada en la posibilidad de sentiry escucharse, tomar conciencia de los pensamientos que generan percepciones, sentimientos, posiciones. Tomar conciencia de las proyecciones que nacen en la ilusión del pensamiento y cuáles realmente nacen en las experiencias. A partir de esta conexión, el sujeto se transforma, se descubre a sí mismo. Y en esa potencia de reconocerse se alcanza la fuerza para la cocreación.

» Conexión con el otro. Fundamentada en la posibilidad y la potencia de escuchar y reconocer todo aquello que eso otro -otros humanos, otros pensamientos, otras experiencias, otros seres, otros territorios- me pueden compartir, me pueden enseñar; aprender a escuchar al otro para reconocer su maestría, con lo que puede alimentarme y nutrirme. A partir de esta conexión, se transforman las relaciones y se dispone a tejer colectivamente, a cocrear.

» Conexión con el pluriverso. Fundamentada en la posibilidad de actuar y retribuir, tomar conciencia de nuestro poder ser, ordenar nuestras acciones individuales hacia un tejido colectivo, que nos permita construir realidades diferentes y retribuir en algo lo que la Tierra nos ha brindado, el alimento, el agua, la vida. Transformar nuestras acciones individualistas de manera que abonemos en la cocreación de otras posibilidades de sentido.

La pedagogía de la conexión es un aporte a la pedagogía decolonial, en cuanto valida la experiencia del proyecto Raíces, ordenándolo y empoderándolo desde la conceptualización de su práctica. En ese sentido, la sistematización evidentemente permite visibilizar un proceso de producción de saber desde un punto de enunciación Otro como es la decolonialidad. Así, los elementos de análisis de la sistematización emergen como saberes de dicha experiencia.

Dichos saberes o conocimientos situados responden al proceso pedagógico del proyecto, que orientó -desde el paradigma de los pueblos indígenas- las relaciones que algunos sujetos hoy tejen consigo mismos, con los demás y con su territorio. 


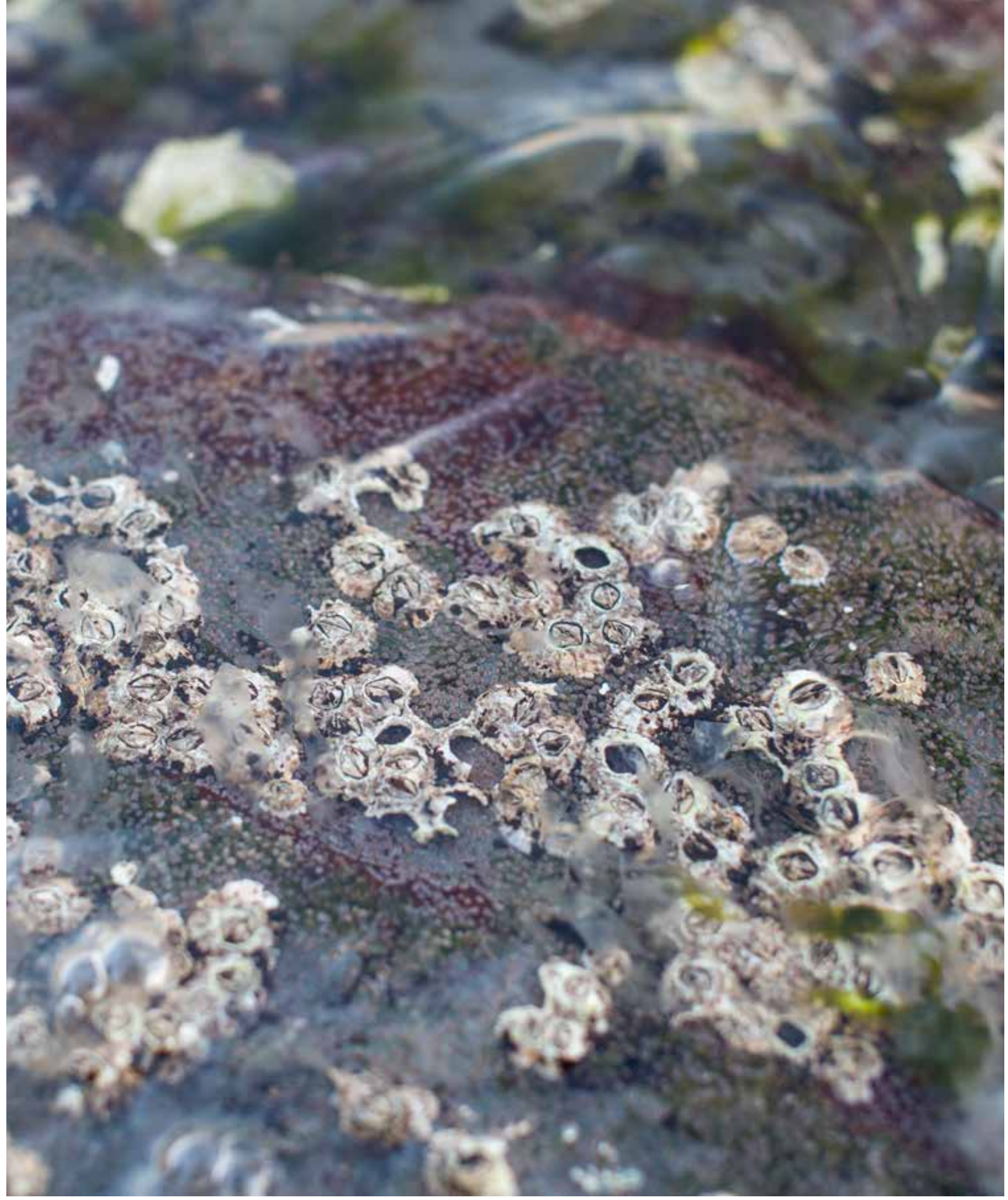

\section{Autora: Ileana Álvarez Reyes \\ Título: \\ Lugar:}




\section{Referencias}

Capó, W., Arteaga, B., Capó, S., Garcia, E., Montenegro, E. y Alcalá, P. (2010). La sistematización de experiencias: un método para impulsar procesos emancipadores. Caracas: Cooperativa Centro de Estudios para la Educación Popular (CEPEP), Editorial Fundación Editorial El Perro y la Rana.

Cendales, L. y Torres, A. (2006). La sistematización como experiencia investigativa y formativa. La piragua. Revista Latinoamericana de Educación y Política, 23, 29 - 38.

Cendales, D., Mariño, G. y Posada, J. (2004). Aprendiendo a sistematizar una propuesta metodológica. Bogotá: Dimensión Educativa.

González, M. (2016). Narrar-nos es formar-nos: las historias de vida en la formación de maestros. Nodos y Nudos, 4(40), $103-115$.

Jara, 0. (2013). Orientaciones teórico-prácticas para la sistematización de experiencias. Recuperado de http://www. cepalforja.org/sistem/bvirtual/

Larrosa, J. (2009). Sobre la experiencia. Aloma, XX, 87-112. Recuperado de http://files.practicasdesubjetivacion.webnode.es/200000018-9863d9a585/_la_experiencia_Larrosa.pdf
Leis, R. (2006). Editorial. Sistematización de experiencias: el encuentro de la palabra y el acto. La piragua. Revista Latinoamericana de Educación y Política, 23, 5-6.

Mejía, M. (2008). La sistematización empodera y produce saber y conocimiento. Bogotá: Ediciones Desde Abajo.

Mejía, M. (2009). La sistematización proceso investigativo o la búsqueda de la episteme de las prácticas. Programa Ondas de Colciencias. Bogotá: Planeta Paz.

Muñoz, J. (2013). Presentación. Entretejidos de la educación popular en Colombia. En L. Cendales, M. Mejía y J. Muñoz (Ed y Comp), Entretejidos de la educación popular en Colombia. Colombia: Ediciones Desde Abajo.

Packer, M. (2014). La ciencia de la investigación cualitativa. Bogotá: Editorial Uniandes.

Rodríguez, E. (2017). La ecología de saberes en la sistematización de experiencias educativas como una apuesta pedagógica decolonial. Intersticios. Intervenciones de la Política y la Cultura, 6(11). Recuperado de https://revistas.unc.edu.ar/index.php/intersticios/article/view/16891

Torres, A. y Mendoza, C. (2013). La sistematización de experiencias en educación popular En L. Cendales, M. Mejia y J. Muñoz (Ed y Comp), Entretejidos de la educación popular en Colombia. Colombia: Ediciones Desde Abajo. 


\section{DIÁLOGO DEL CONOCIMIENTO}

La autora logra en este artículo sintetizar muy bien lo que fue el proceso de sistematización que realizó con siete estudiantes, de las salidas pedagógicas que hicieron durante cuatro años (2011-2014) para recoger los saberes ancestrales de diferentes comunidades campesinas de varios municipios cerca de Bogotá.

Explica los fundamentos teóricos que orientaron este proyecto denominado "Raíces", y el camino metodológico que siguieron paso a paso. Describe las herramientas que constituyeron para trabajar con dichas comunidades y el tratamiento que le dieron a la información. Igualmente expone los resultados del proceso y las conclusiones a las que llegaron, de cara a los objetivos que se habian propuesto.

Así, en el texto se muestra la inmensa riqueza que aún existe en relación con los saberes que portan estas comunidades, muchas veces desconocidos o subvalorados por la sociedad. Reivindicar estos saberes y ponerlos a disposición de la formación de niños y jóvenes en los colegios de nuestro país es un propósito que queda abierto para aprovechar el trabajo realizado y estimular a otras comunidades educativas para que emprendan caminos similares.

Dos aportes para seguir dialogando con el proyecto:

1. Hubiera sido interesante que se precisara más en qué sentido el pensamiento ancestral que desentrañaron es decolonial. Hay que analizar bien este asunto, pues el denominado pensamiento ancestrales hoy, en la vida de las comunidades, el resultado de un largo proceso de mestizaje en el que intervienen muchas tradiciones. Lo decolonial, en el sentido emancipador que el proyecto quiere darle, habría que descubrirlo a partir de criterios que no son fáciles de establecer. Incluso, habria que atreverse a pensar si hay algo de colonialidad aún en los saberes de las comunidades. Y quedan las preguntas: ¿Quién emancipa a quién?; ¿qué emancipa?; ¿frente a qué nos emancipamos? Explicitar esto es importante para mantenernos en una postura crítica, incluso frente a muchos supuestos a veces damos por sentados sin más.

2. Y ¿esto cómo funciona en la escuela? La idea de una pedagogía de la conexión es muy sugestiva. Llevarla en su plenitud a la vida de la escuela es un reto muy exigente, pues ayudaría a actualizarla y ponerla de cara a muchos desafios que hoy enfrentan las nuevas generaciones. Ojalá se pueda difundir también la experiencia de lo que ha significado llevar estos trabajos a la escuela y los logros y resistencias que esto genera.

Alejandro Álvarez Gallego Profesor Universidad Pedagógica Nacional 